\title{
PERANCANGAN MEDIA INFORMASI TORAJA PADA UPACARA RAMBU SOLO'
}

\section{DESIGNING TORAJA INFORMATION MEDIA ON RAMBU SOLO’CEREMONY}

\author{
Asmita Jatir ${ }^{1}$, Muh. Saleh Husain ${ }^{2}$, Aswar ${ }^{3}$ \\ ${ }^{123}$ Fakultas Seni dan Desain Universitas Negeri Makassar \\ Coresponden Author: Asmithjtr22@gmail.com
}

\begin{abstract}
ABSTRAK
Perancangan ini bertujuan untuk memberikan informasi yang factual, pesan yang disampaikan memberi penerangan, aktraktif untuk dilihat dan terjangkau oleh orang banyak. Penelitian ini menggunakan metode kualitatif yaitu melakukan riset yang bersifat deskriptif dan cenderung menggunakan analisis dengan pendekatan induktif, data yang diperoleh dari kajian kepustakaan, observasi, wawancara yang dilakukan dengan pemuka adat dan dokumentasi. Pada konsep perancangan media utama, dimulai dari pembuatan naskah, storyline, storyboard, sketsa elemen visual, shooting, recording, editing hingga proses akhir berupa render video. Hasil dari perancangan media informasi ini adalah film dokumenter menggunakan rasio 16:9, resolusi 1080 HD dan berjudul The Fade of Ritual Values. Pembuatan film dokumenter juga didampingi dengan media pendukung berupa cover $C D$ dan media promosi berupa $t$-shirt, sticker, $x$-banner dan totebag.
\end{abstract}

Kata Kunci: Perancangan. Media Informasi. Toraja. Upacara Rambu Solo’.

\section{ABSTRACT}

This design aims to provide factual information, the message conveyed provides information, is interesting to be seen and affordable by many people. This research uses a qualitative method that is doing research that is descriptive and tends to use analysis with an inductive approach, data obtained from literature reviews, observations, interviews conducted with traditional leaders and documentation. the main media design concepts, ranging from making scripts, story lines, storyboards, making visual sketch elements, shooting, recording, editing to the final process in the form of video rendering. The results of this information media design is a documentary film use a ratio of 16: 9, 1080p HD resolution and titled "The Fade of Ritual Values". Documentary filmmaking is also supported by supporting media in the form of CD covers and promotional media in the form of $t$-shirts, stickers, $x$-banners and totebags.

Keywords: Designing. Information Media. Toraja. Rambu Solo’ Ceremony.

\section{PENDAHULUAN}

Indonesia merupakan negara majemuk yang memiliki suku, ras, bahasa dan agama yang berbeda-beda. Salah satu suku yang unik di Indonesia yaitu suku Toraja. Kata Toraja berasal dari Bahasa bugis, To Riaja, yang berarti "orang yang berdiam di negeri atas". Toraja terkenal akan ritual kematian, rumah adat tongkonan dan juga ukiran-ukiran yang khas. Sebelum abad ke$\mathrm{XX}$, Suku Toraja tinggal di desa-desa otonom. Mereka masih menganut animisme dan belum tersentuh oleh dunia luar. Pada tahun 1913, misionaris Belanda datang dan menyebarkan agama Kristen. Sejak tahun 1990-an Toraja mengalami tranformasi budaya, dari masyarakat berkepercayaan tradisional dan agraris, menjadi masyarakat yang mayoritas beragama Kristen dan mengandalkan sektor pariwisata yang terus meningkat. Sebagai kelompok ataupun suku yang berbeda dengan yang lainnya, Suku Toraja juga memiliki budaya yang menjadikannya unik di tengah-tengah kemajemukan suku-suku bangsa di Indonesia. Salah satu budaya yang 
sangat terkenal dari Toraja, bahkan dikenal sampai mancanegara, adalah Rambu Solo' atau upacara pemakaman. Menurut (Tangdilintin, L. T., 2009:48) Istilah aluk Rambu Solo' terbangun dari tiga kata, yaitu Aluk (keyakinan), Rambu (asap atau sinar), dan Solo' (turun). Dengan demikian, Aluk Rambu Solo' dapat diartikan sebagai upacara yang dilaksanakan pada waktu sinar matahari mulai turun (terbenam). Sebutan lain untuk upacara ini adalah aluk rampe matampu'. Aluk artinya keyakinan atau aturan, rampe artinya sebelah atau bagian, dan matampu' artinya barat. Jadi, makna aluk rampe matampu' adalah upacara yang dilaksanakan di sebelah barat dari rumah atau tongkonan. Upacara Rambu Solo' citranya sudah mendunia bahwa hanya orang yang mempunyai keturunan bangsawanlah yang berhak melaksanakan upacara Rambu Solo', melainkan semua masyarakat Toraja berhak melaksanakannya. Akibat masuknya para penjaja dan agama lain yang membuat nilai-nilai adat pada Rambu Solo mulai bergeser. Oleh karena itu berdasarkan dari permasalahan tersebut penulis merancang sebuah media informasi yang berjudul "Perancangan Media Informasi Toraja Pada Upacara Rambu Solo"'. Yang bertujuan untuk memberikan informasi yang factual, pesan yang disampaikan memberi penerangan, atraktif untuk dilihat dan terjangkau oleh orang banyak.

\section{METODE PENELITIAN}

Peneliti menggunakan metode kualitatif yaitu melakukan riset yang bersifat deskriptif dan cenderung menggunakan analisis dengan pendekatan induktif. Objek dari perancangan ini yaitu Rambu Solo' yang dimana mengangkat perubahan yang terjadi akibat masuknya agama Kristen dalam sebuah media informasi yang berlokasi di Jl. Singki, Rantepao, Kab. Toraja Utara dan Sa'dan To' Barana'. Teknik pengumpulan data yaitu: Mencari literaturliteratur yang sesuai perancangan ini melalui buku atau media cetak lainnya. Juga dari internet seperti artikel dan komentar seseorang. Survey dan mendatangi langsung lokasi tempat pengumpulan data yaitu di Desa Sumpia Kecamatan Tikala, Toraja Utara. Dengan melihat angel camera yang akan digunakan pada perancangan film documenter ini nantinya.
Wawancara dilakukan dengan bertatap muka secara langsung dengan masyarakat dan To Minaa untuk memberikan beberapa pertanyaan agar mendapatkan informasi yang jelas tentang upacara Rambu Solo'. Tak hanya proses yang ditanyakan tetapi, juga perkembangan awal mula upacara pemakaman ini dilaksanakan sampai saat ini yang sudah masuknya agama Kristen dan sudah mengikuti jaman modernisasi. Untuk Dokumentasi diambil menggunakan kamera DSLR dan handphone pada saat wawancara dan observasi lapangan dilakukan.

\section{HASIL DAN PEMBAHASAN}

\section{Konsep Desain}

Dari analisis data yang telah dibuat dan akan dirancang pada perancangan ini, maka konsep desain yang diangkat pada Upacara Rambu Solo' yaitu "Nilai Adat" yang dimana sudah mulai memudar akibat masuknya budaya lain yang mengaku katanya adat, tapi adatnya itu tak seperti yang semestinya dari nenek moyang orang Toraja (Tato Dena')

Mengikut Theodorus Kobong (2008), sejak tahun 1970-an, gereja sudah kehilangan kawalan atas tingkah laku orang Kristian. Pestapesta ritual kematian, dikembangkan secara berlebihan dan memberi kesan seolah dibuatbuat. Orang-orang tua mengatakan bahwa pada jaman dulu, upacara kematian itu lebih sederhana. Akibat meningkatnya kekayaan material, banyak unsur dalam adat yang ditambah dan dimodifikasi. Itu kerana perbuatan orang Kristian yang mengubah ritual-ritual itu menjadi pameran keberhasilan. Itulah kritik orang-orang tua, khususnya mereka yang masih menganut Aluk Todolo. Kritik juga datang dari pihak pemuda. Pesta-pesta adat adalah penghamburan semata. Dalam perancangan ini tak akan pernah lepas dari unsur-unsur perancangan Desain Komunikasi Visual yang mencakup segala hal tentang warna, tipografi, bentuk/gaya, citra dan elemen-elemen desain lainnya yang kemudian dikaitkan dengan ide cerita yang telah dibuat.

\section{Sumber Inspirasi}

Bersumber dari Toraja yang memiliki wisata yang begitu indah ditambah upacara adat 
yang unik yaitu, Rambu Tuka \& Rambu Solo' yang dikenal hingga mancanegara maka, perancang tertarik untuk membuat film dokumenter yang berdurasi 5-7 menit dengan pengambilan gambar teknik sinematografi tentang proses upacara Rambu Solo'. Sudah terkenalnya upacara Rambu Solo' ini membuat perancang tertantang melakukan penelitian untuk mengetahui dengan jelas tentang Rambu Solo'. Hasil dari penelitian mengatakan bahwa nilai-nilai adat pada upacara Rambu Solo' saat ini sudah mulai hilang diakibatkan masuknya budaya barat. Para pemangku adat hanya bisa geleng-geleng kepala melihat upacara Rambu Solo' dari nenek moyangnya memudar.

Dalam pemilihan logo/brand diambil dari tanduk tedong yang merupakan hewan yang dikorbankan untuk kendaraan jiwa orang mati pada upacara Rambu Solo' dan tongkonan identitas dari Toraja. Tak lupa juga slogan untuk menarik minat para penikmat film dokumenter ini nantinya.

\section{Tipografi}

Ada beberapa pemilihan tipografi yang digunakan di film ini, yaitu tipografi pada merek/logo, slogan/tagline, creadit title dan teks/subtitle. Jenis huruf/font yang dipilih adalah huruf handwriting dan perpaduan antara tanduk tedong dan tongkonan yang bentuknya di modernkan, huruf akan dibuat sederhana agar jika dilihat orang langsung paham.

1. Pada merek/logo tanduk tedong dan tongkonan dan digabungkan dengan huruf/font handwriting.

2. Font slogan mengunakan font brush (tulisan kuas).

3. Font untuk tesk/subtitle yang akan digunakan adalah huruf/font Times New Roman.

\section{Warna}

Sederhananya, warna bisa mempengaruhi kita secara emosional, psikologis, dan bahkan secara fisik, seringkali tanpa kita sadari. Warna dalam film dan video bisa membangun harmoni atau ketegangan dalam suatu adegan, atau memperhatikan tema kunci. Saat menceritakan sebuah cerita, warna bisa :
1. Mendapatkan reaksi psikologis dengan penonton

2. Menggambarkan fokus ke detail yang signifikan

3. Mengatur nada film

4. Mewakili sifat karakter

5. Tampilkan perubahan atau lengkungan dalam cerita

Pada film ini nantinya skema warna komplementer yang digunakan. Kontras drama (yaitu, hangat vs sejuk) seperti halnya warnawarna yang ada pada ukiran Toraja. Warna komplementer hidup saling berhadapan pada roda warna. Misalnya, warna oranye dan hijau adalah warna pelengkap yang biasa. Warna duel sering dikaitkan dengan konflik, baik internal maupun eksternal. Tidak masalah pemilihan warnanya, warna pelengkap menggabungkan warna hangat dan sejuk untuk menghasilkan kontras yang tinggi, ketegangan yang dinamis di film ini. Juga warna hitam yang digunakan pada logo dan slogan Rambu Solo' membawa suasana kedukaan.

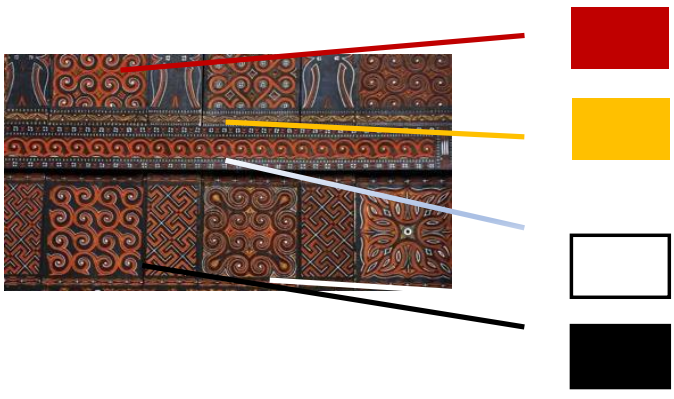

Gambar 1 empat warna ukiran Toraja

\section{Ide dan Sketsa}

1. Narasi

Menampilkan trailer film dengan singkat yang menjelaskan keseluruhan dari film. Kemudian mulai membahas tentang apa itu Rambu Solo' dan diteruskan dengan perubahan yang terjadi pada Rambu Solo' sekarang ini yang diakibatkan masuknya agama Kristen, dimana adatnya itu bukan adat lagi. Dan sebagai penutup akan dijelaskan harapan untuk membedakan adat dan agama. 
2. Brand

Pada eksplorasi pesan visual pada logo seperti yang diusung yaitu tanduk tedong dan tongkonan juga tipografi hand drawing Rambu Solo’.

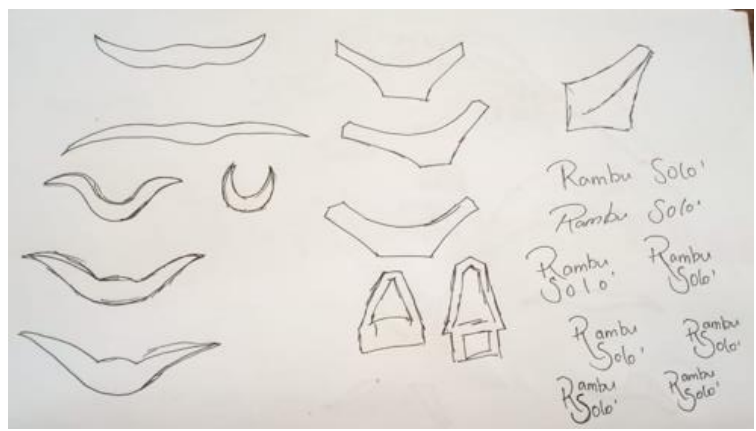

Gambar 2 Sketsa Logo/Brand

\section{Eksplorasi Ide}

1. Naskah

Naskah pada film dokumenter upacara Rambu Solo' ini dibagi menjadi 2 bagian, yaitu:

a. Act. 2 (Intisari Cerita)

- Rambu Solo' merupakan upacara kematian yang dilakukan oleh orang Toraja, dan dilakukan saat matahari mulai tenggelam.

- Apabila upacara tidak dilakukan, maka masyarakat meyakini bahwa arwah yang baru saja meninggal tersendak, sehingga tidak sampai kepada nenek moyangnya.

- Tedong atau biasa dikenal dengan Kerbau, Dipercaya sebagai kendaraan arwah menuju Puya', dan semakin banyak jumlah yang dipotong, semakin cepat pula arwahnya sampai.

- Aturan sebenarnya yaitu, masyarakat hanya membutuhkan maksimal 24 ekor Tedong, Namun sayangnya dijaman yang modern saat ini terlalu banyak jumlah tedong yang dipotong, hingga mencapai 300 ekor hanya semata-mata karna kesombongan belaka.

- Tak hanya itu, tradisi dan budaya yang lainnya pun berubah, seperti pakaian yang mulai diabaikan serta, mainan tradisionalpun sudah hampir punah.

b. Act. 3 (Kesimpulan)
- Perubahan ini terjadi karna salah satunya yaitu, adanya dampak globalisasi dan modernisasi.

2. Storyline

1. Act 1 (Pengenalan)

- Suasana lokasi Rambu Solo', Menampilkan keseluruhan gambar lokasi Rambu Solo' dari atas.

- Menampilkan potongan-potongan dari keseluruhan film, Logo dan slogan.

- Suasana duka, menampilkan keluarga yang sedang melampiaskan kesedihannya. Suasana Rambu Solo', mengangkat peti ke pemakaman. Menampilkan tulisan nama pembuat film.

2. Act 2 (Intisari Cerita)

- Suasana kampung, menampilkan panorama dan masyarakat yang mengantar mayat ke pemakaman.

- Suasana acara, saat mayat di bawah ke pemakaman

- Suasana acara, menampilkan penerimaan tamu dihari pertama.

- Suasana acara, menampilkan persiapan untuk menguburkan mayat

Suasana acara, menampilkan pemotongan kerbau dihari ketiga acara.

- Suasana acara, menampilkan suasana saat ibadah sebelum dibawah ke pemakaman.

- Suasana acara di Sa'dan To'barana, menampilkan tarian pa'randing (tari perang) dan ma'badong.

3. Act 3 (Kesimpulan)

- Suasana acara, menampilkan pantarima tamu.

- Suasana kampung yang diambil dari atas sambil mayat di antarkan ke pemakaman

- Kuburan, yang diambil dari atas menjauhi kuburan. 
3. Storyboard

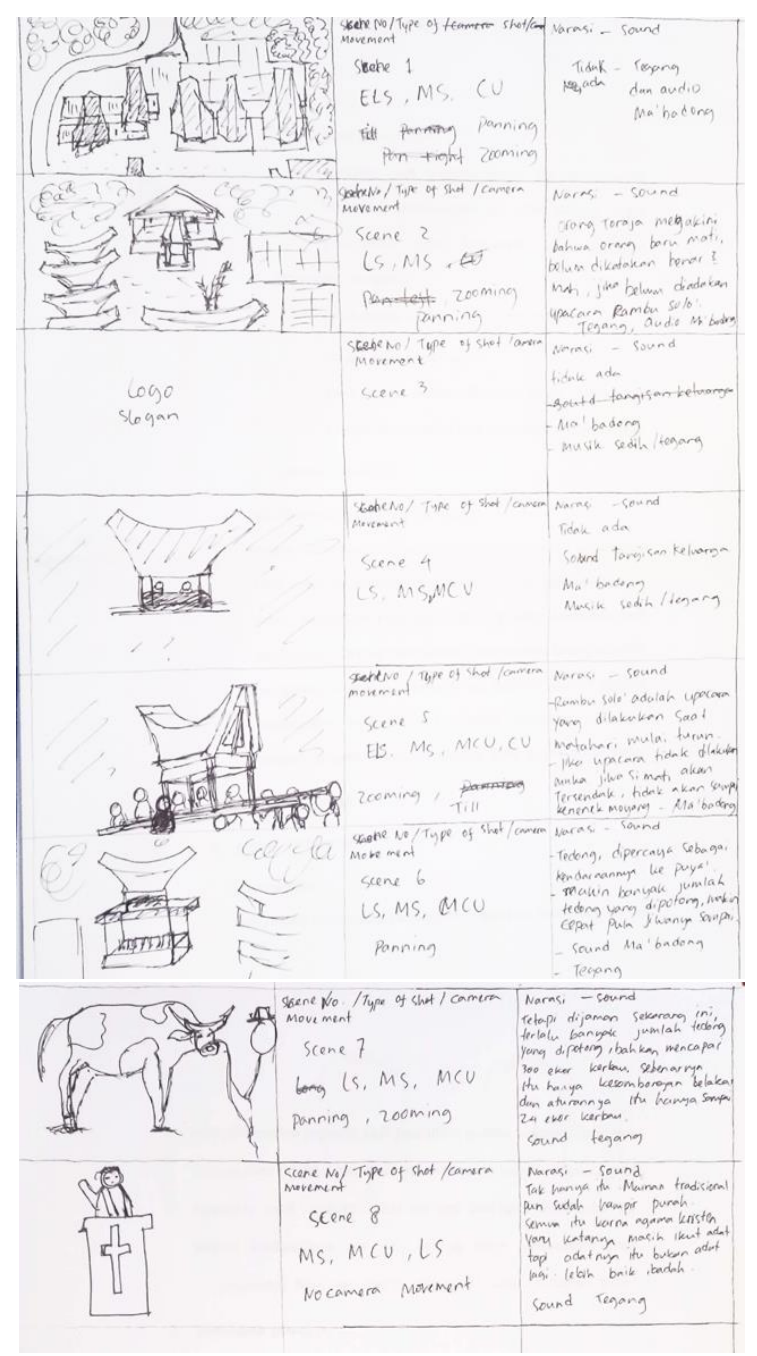

Gambar 3 Storyboard

4. Media Pendukung

Berikut adalah media pendukung untuk penunjang media utama:
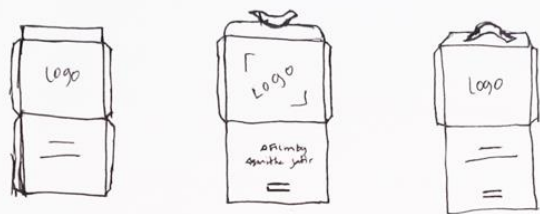

Gambar 4 Sketsa Cover CD
5. Media Promosi

Visual merchandise adalah media promosi yang tepat untuk mempromosikan sebuah film, seperti:

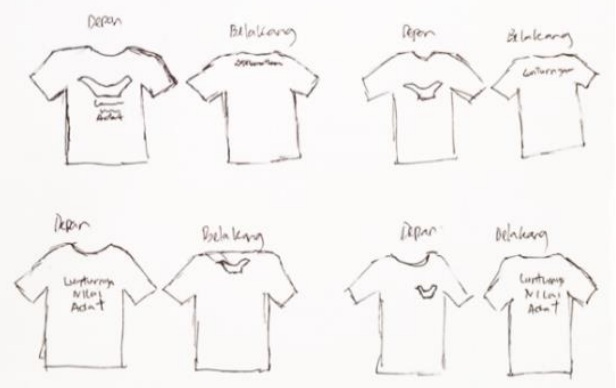

Gambar 5 Sketsa Desain Baju

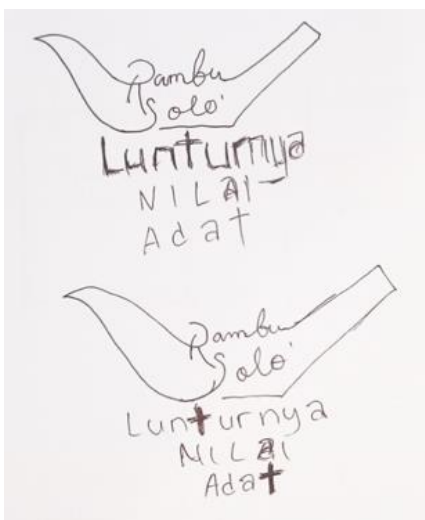

Gambar 6 Sketsa Sticker
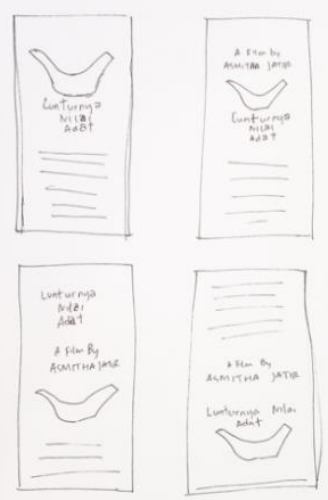

Gambar 7 Sketsa X-Banner 
6. Element Visual
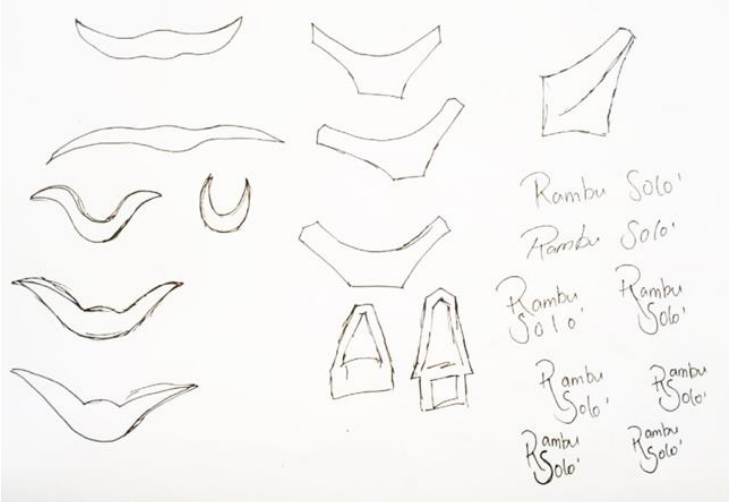

Gambar 8 Sketsa Logo/Brand

\section{Implementasi Digital}

\section{Shooting}

Tidak ada rekayasa dalam proses shooting, hanya sesuai dengan alur upacara Rambu Solo' dilakukan.

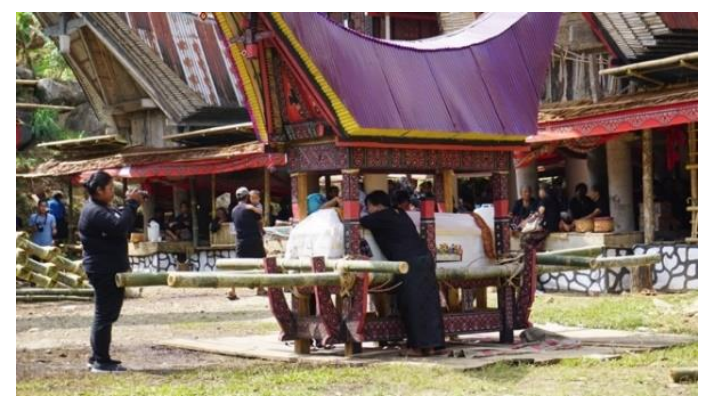

Gambar 9 Proses Pengambilan Gambar DSLR

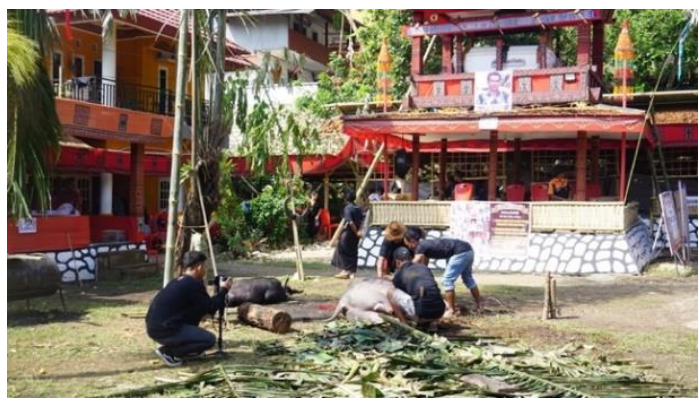

Gambar 10 Proses Pengambilan Gambar DSLR

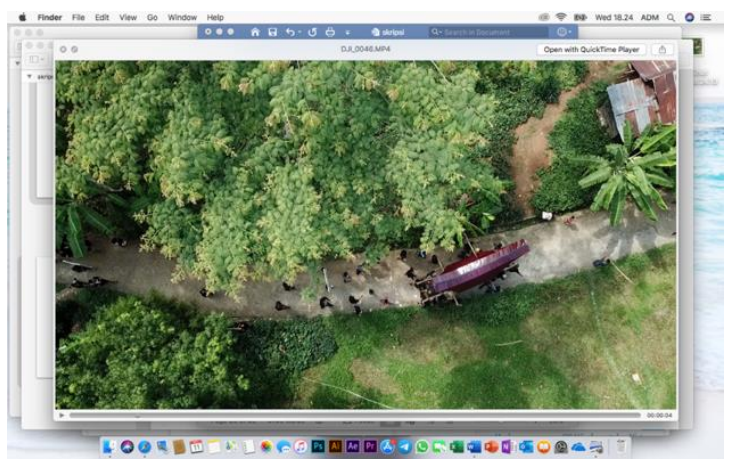

Gamabar 11 Proses Pengambilan Gambar Drone

Peralatan yang digunakan saat shooting yaitu:

a. Drone DJI Mavic Pro

b. 2 Unit Kamera Canon 60D

c. Kamera Sony a6000

d. 2 Lensa Canon Standart 18-55

e. Lensa Canon Standart 16-50

f. DJI Osmo Mini

g. Monopod dan Tripod

2. Recording

Dalam recording pada film ini dilakukan dengan 2 cara, yaitu dari hasil record kamera yang diambil saat acara berlangsung dan juga record menggunakan handphone untuk narasi setelah shooting dilakukan.

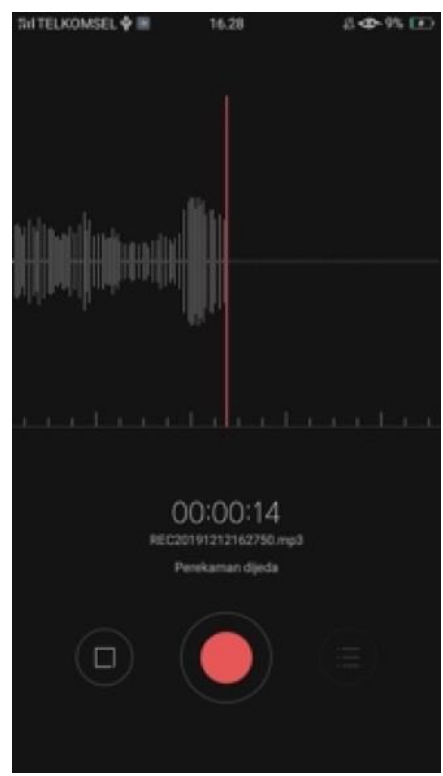

Gambar 12 Proses Recording di Handphone 


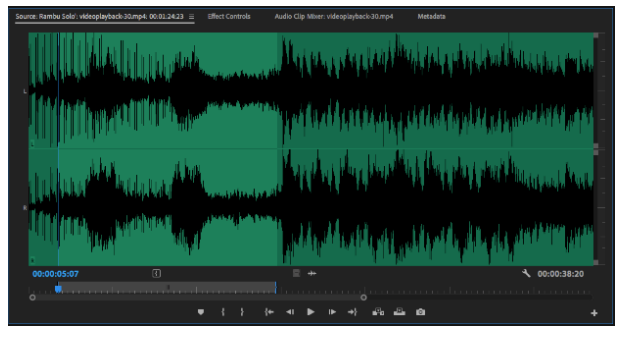

Gambar 13 Proses Recording di DSLR

\section{Video Editing}

Dalam video editing ini, ada beberapa proses yaitu, cut to cut, color grading, memasukkan subtitle, elemen-elemen visual. Semua proses ini memakai software Adobe Premiere Pro CC 2019.

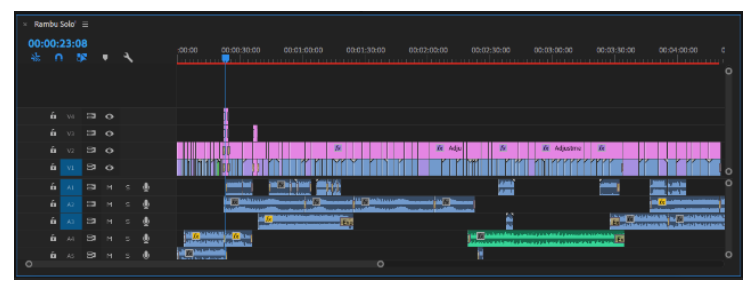

Gambar 14 Proses Cut to Cut

Proses cut to cut adalah menggabungkan gambar ke gambar yang dihasilkan dari shooting. Dalam proses editing tak hanya itu yang dilakukan, ada juga color grading.

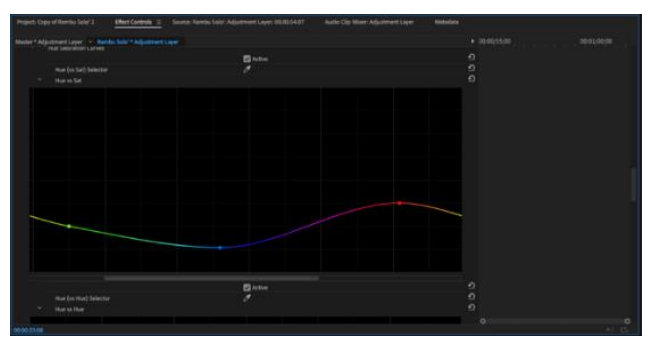

Gambar 15 Proses Color Grading

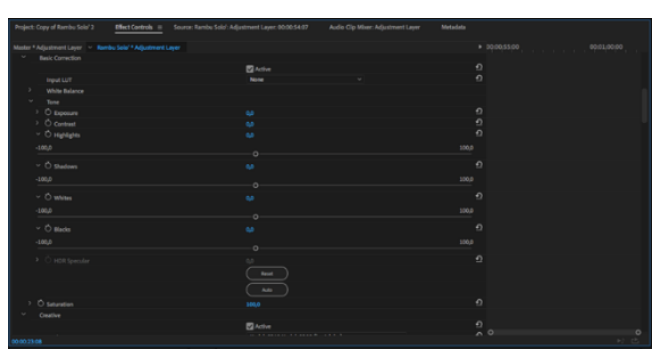

Gambar 16 Proses Color Grading
Seperti pada konsep warna awal, perancang memakai warna-warna asli dari Toraja yaitu kuning, merah, putih dan hitam. Yang dimana hasilnya lebih menambah gairah dan menarik minat para audience untuk menikmati film dokumenter upacara Rambu Solo' "The Fade of Ritual Values".

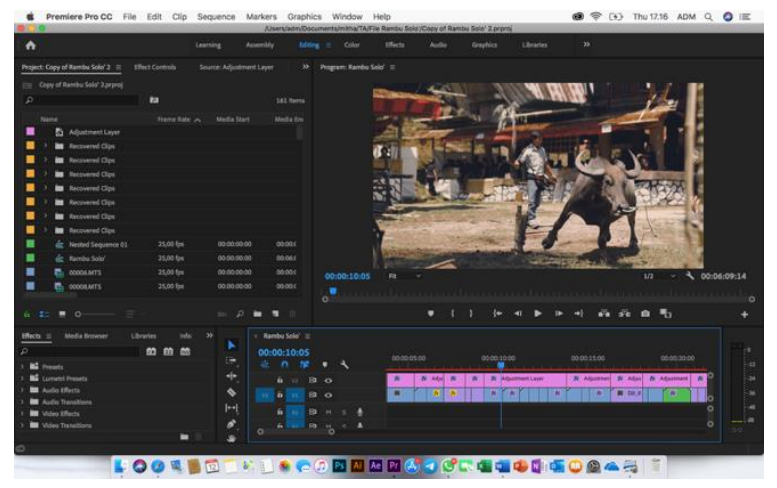

Gambar 17 Proses Penulisan Subtitle

Adapun elemen-elemen visual yang membuat film ini makin kece.

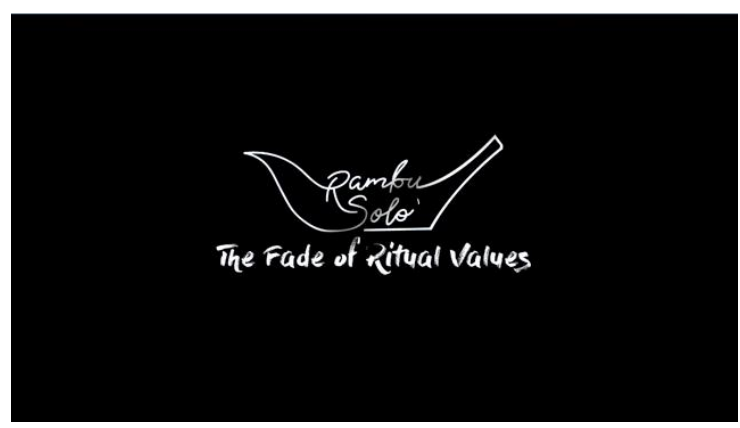

Gambar 18 Proses Penerapan Elemen-Elemen DKV

4. Sound Editing

Sound sangat berpengaruh dalam film karena bisa membuat film lebih hidup dan asik sesuai dengan suasana yang dibangun pada film tersebut. Ada 3 tahap pengeditan sound pada film ini, yaitu Dynamics Processing, Multiband Compressor, Parametric Equalizer. 


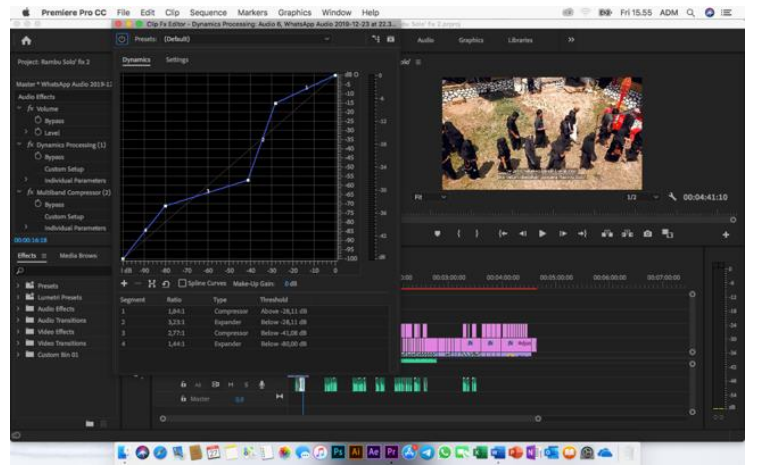

Gambar 19 Dynamics Processing

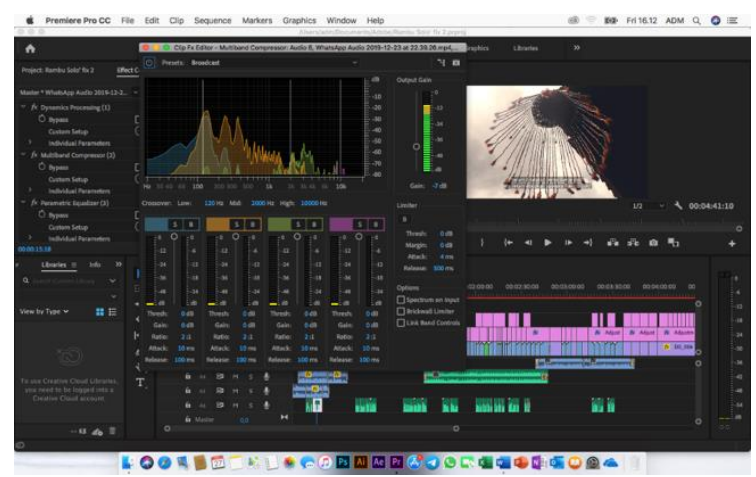

Gambar 20 Multiband Compressor

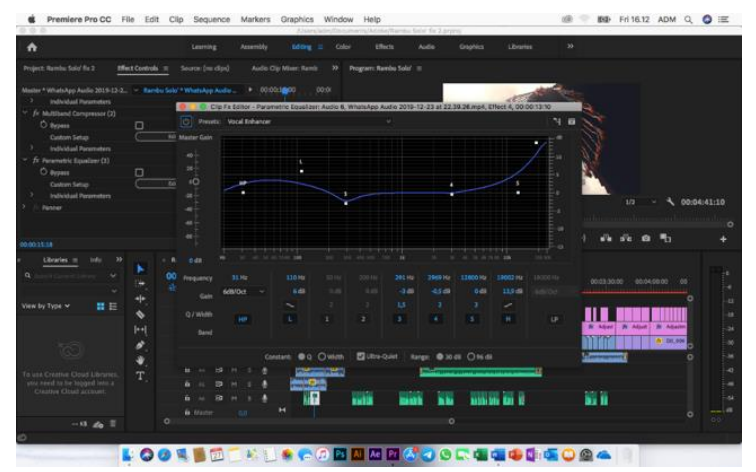

Gambar 21 Parametric Equalizer

\section{Pembahasan}

Pada film dokumenter ini menjelaskan sebuah ritual kematian yang dilakukan oleh masyarakat Toraja turun temurun dari nenek moyangnya yang hingga saat ini mulai memudar akibat banyaknya pengaruh yang masuk. Dimulai dari menampilkan potongan-potongan film yang akan membuat para penonton penasaran akan kelanjutan film ini nantinya, yaitu menampilkan keseluruhan lokasi dari atas dan potongan dari setiap scene yang ada pada film. Dan yang terakhir dibuat lebih menyinggung agar masyarakat Toraja sadar dengan apa yang telah dilakukan oleh mereka yang masuk membawa budaya yang mengaku masih ikut adat tapi, itu bukan lagi adat dari nenek moyang yang sebenarnya.

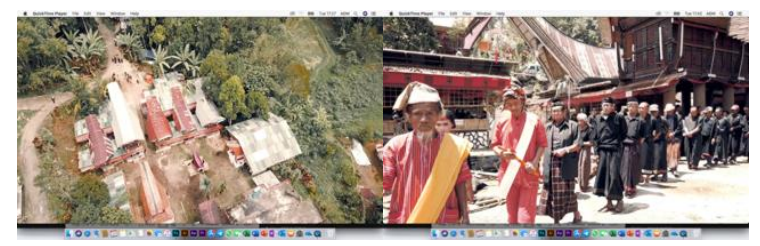

Gambar 22 Scene 1

Pada gambar 1.23 scene 1 ditampilkan keseluruhan lokasi upacara dilakukan dan dengan dilanjutkan proses upacara dari pantarima tamu (penerimaan tamu) hari pertama dan hari kedua juga pemotongan tedong (kerbau) dan terakhir penguburan. Lalu masuklah logo dan slogan untuk memancing rasa penasaran penonton. Sudut pengambilan gambar (camera angel) bird eye, high angel dan eye level, komposisi dari segi ukuran (field of view) head shot, mid shot, full shot dan long shot, komposisi dari segi banyaknya manusia group shot, juga pandangan objek yaitu headroom dan noseroom.

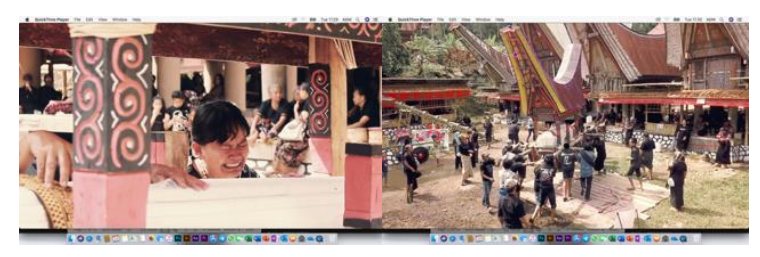

Gambar 23 Scene 2

Scene 2 gambar 1.24, ditampilkan gambar yang sedang berduka mendalam karna ditinggal oleh orang yang disayangi agar lebih penasaran lagi dan akan membawa suasana haru dalam film. Dan dilanjutkan dengan pengangkatan mayat ke pemakaman, layer hitam dengan memunculkan nama perancang film. Sudut pengambilan gambar dibuat Medium Close $U p$ agar dapat terlihat jelas ekspresi objek dan juga audio asli dari Lokasi diaktifkan. 


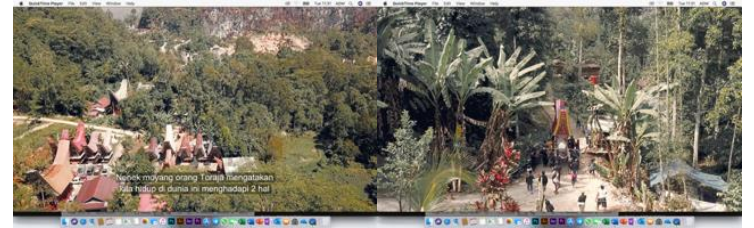

Gambar 24 Scene 3

Pada scene 3 ini menjelaskan tentang Rambu Solo' untuk memberikan informasi Dimana dalam pengambilan gambar eye level dengan teknik zooming dan panning, juga tambahan narasi agar audience dapat mengerti. Menampilkan lokasi upacara dan tongkonan menggunakan tipe bird's eye view.

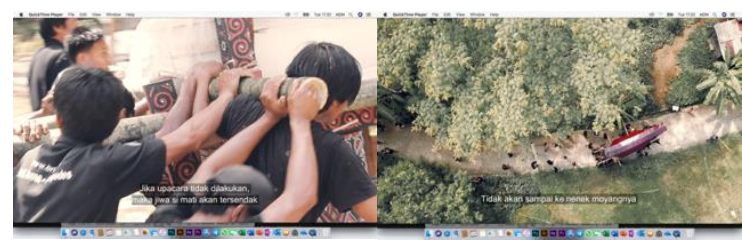

Gambar 25 Scene 4

Gambar 1.26 menampilkan masyarakat yang sedang mengangkat jenazah untuk diantar ke pemakaman dengan suasana penuh kegembiraan walaupun capek. Dengan menggunakan sudut pengambilan gambar bird eye, high angel, eye level dan low angel, komposisi dari segi ukuran mid shot, medium shot dan long shot, grup shot dan foreground.

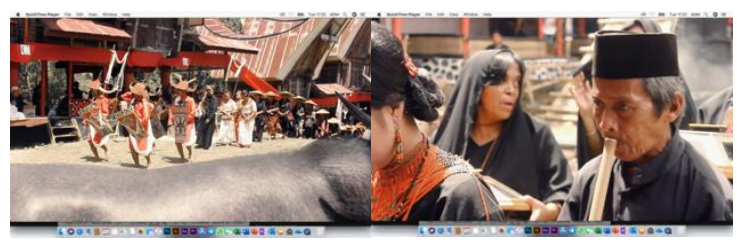

Gambar 26 Scene 5

Dalam pelaksanaan upacara Rambu Solo' jika seorang laki-laki yang berjiwa pejuang meninggal akan dihormati dengan menampilkan sebuah pertunjukan tarian pa'randing (perang) dan juga ada diiringi dengan permainan suling bombo (bamboo). Nah, terlihat pada gambar diatas, mengapa demikian, karna diharapkan audience juga dapat bisa melihat upacara yang sebenarnya dilakukan, bukan hanya melihat upacara saat ini yang sudah masuk doktrin dari budaya lain. pada pengambilan gambar dengan foreground atau ada sesuatu didepan objek, jenis komposisi dari banyaknya manusia yaitu group shot, komposisi dari segi ukuran medium close up, full shot dan long shot, sudut pengambilan gambar (camera angel) high angel dan eye level.
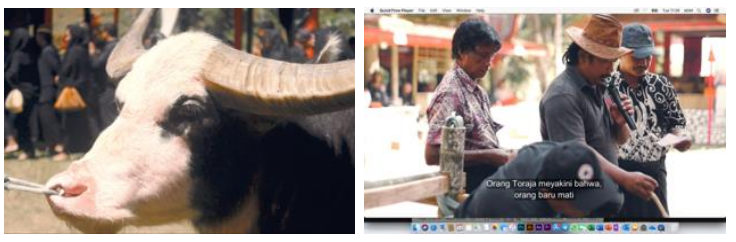

\section{Gambar 27 Scene 6}

Gambar 1.28 masuklah pada sebuah penjelasan inti dari film ini yang dimana tedong adalah kendaraan si mati orang Toraja untuk sampai ke puya' (alam roh) Bersama nenek moyangnya. Juga lebih dijelaskan melalui narasi bahwa pada jaman sekarang terlalu banyak jumlah tedong yang dikorbankan, bahkan mencapai 300 ekor dan aturannya dari nenek moyang hanya 24 ekor. Karna prinsip orang tua, semua manusia akan mati. Jadi, jika mengorbankan terlalu banyak tedong akan membuat populasinya akan menurun, trus kalau begitu anak cucunya nanti mau korbankan apa jika sudah habis. Camera angel yang digunakan high angel, eye level, head shot, mid shot, full shot dan group shot.

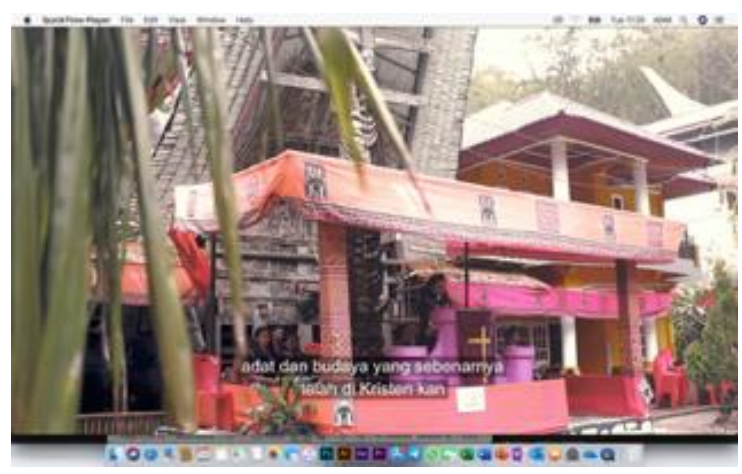

Gambar 28 Scene 7

Gambar 1.29 disini menandakan bahwa pada upacara Rambu Solo' telah mengalami perubahan yaitu masuknya budaya lain dan menggantikan mainan tradisional dengan ibadah mereka. Dari gambar diatas juga dapat menyadarkan masyarakat Toraja akan hal itu. Teknik foreground dan panning yang digunakan pada film ini dengan full shot dan grup shot. 


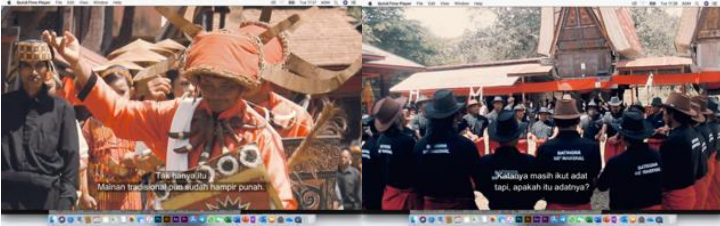

Gambar 29 Scene 8

Nah pada scene 8 ini adalah upacara Rambu Solo' yang dirindukan oleh tetua adat (Nek Sando), dimana jika seorang mantan pejuang dimasa lalu meninggal akan dihormati dengan iringan tarian pa'randing. Tak lupa juga ada tarian ma'badong dimana tarian ini untuk menyurahkan rasa kesedihan untuk si mati lakilaki maupun perempuan. Video ini diambil oleh perancang di Sa'dan To' Barana dan pengambilan video tempat penelitian itu tak ada. Pada video ini teknik dan moment sangat dipentingkan maka dari itu perancang menggunakan beberapa sudut pandang dan teknik zooming agar audience dapat menikmati dengan asik.

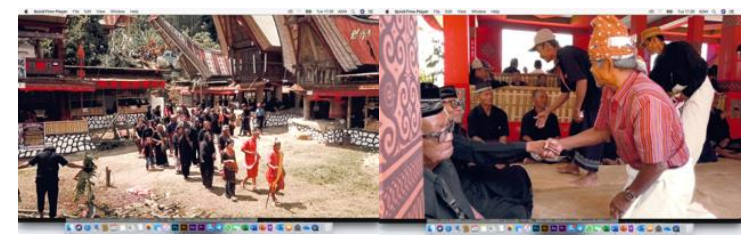

Gambar 30 Scene 9

Gambar 1.31 prosesi penerimaan tamu keluarga maupun kerabat dimana pakaian yang digunakan juga berbeda-beda, terlihat jelas silaturahmi yang tergambar pada film ini. Dalam scene ini lebih diutamakan momen yang terekam di banding teknik yang digunakan.

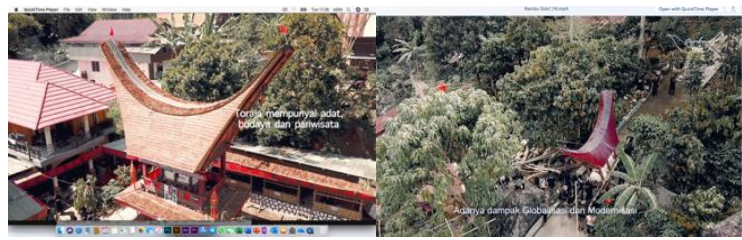

Gambar 31 Scene 10

Gambar 5.10 dijelaskan bahwa akibat adanya pengaruh globalisasi dan modernisasi adat dan budaya di Toraja sudah mulai memudar. Nah dari pernyataan itu perancang ingin membuat audience terutama masyarakat Toraja tersadar akan semuanya.

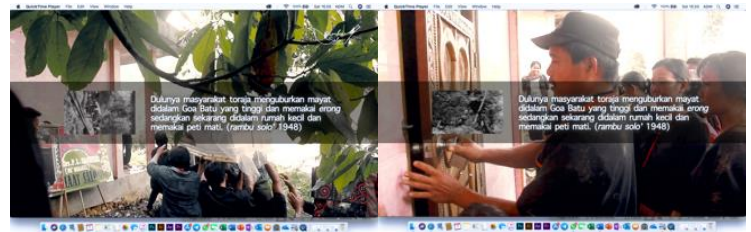

Gambar 32 Scene 11

Salah satu yang jarang orang tau kebenarannya karna telah tertutupi oleh destinasi wisata di Toraja seperti, Londa, Lokko Mata' dan Kete' Kesu' bahwa masyarakat Toraja masih di kuburkan di dalam Goa, dalam batu maupun di pinggiran tebing itu ternyata sudah dominan beralih kepemakaman dalam rumah kecil seperti halnya orang Kristen menguburkan mayat. Maka dari itu dalam scene ini perancang membuat perbedaan dulu dan sekarang.

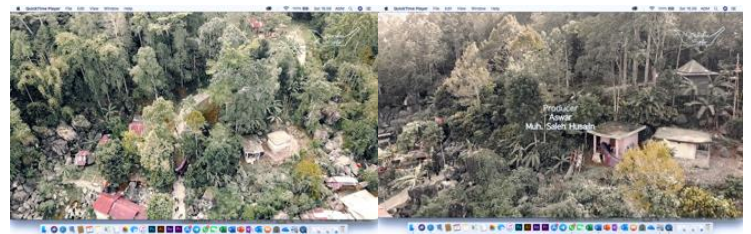

Gambar 33 Scene 12

Memperlihatkan keindahan kampung dan lingkungan acara yang dilanjutkan dengan credit title. Pengambilan gambar menggunaka bird eye level agar keindahan Toraja tergambarkan.

\section{Media Pendukung}

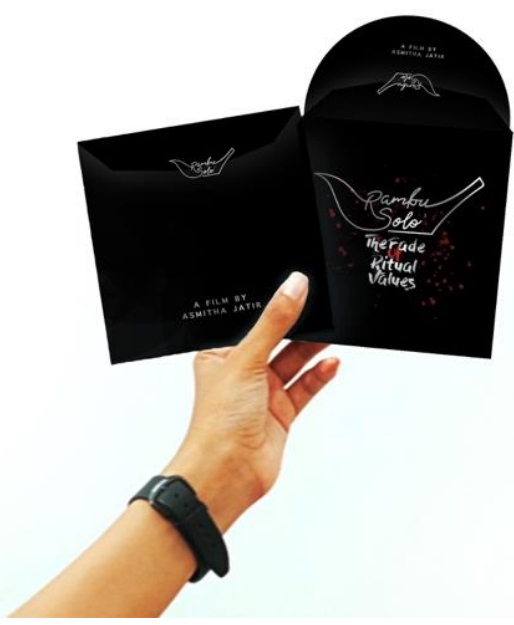

Gambar 34 Cover CD dan Sticker CD 


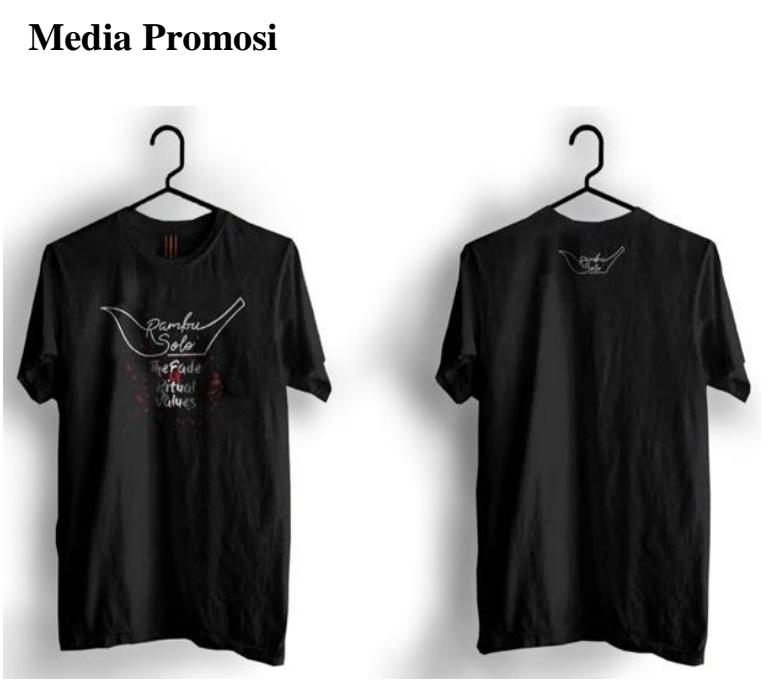

Gambar 35 Baju Film
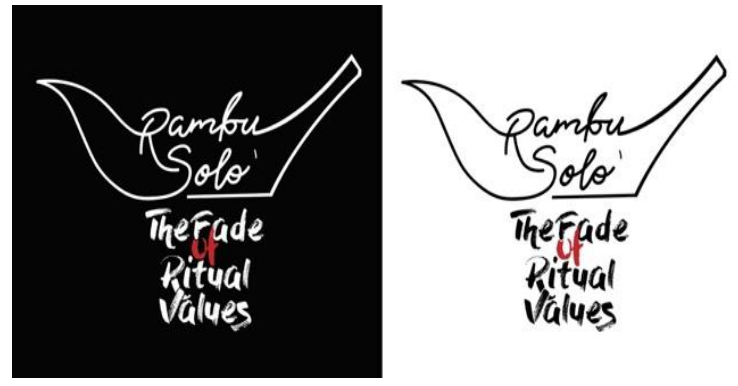

Gambar 36 Sticker Film

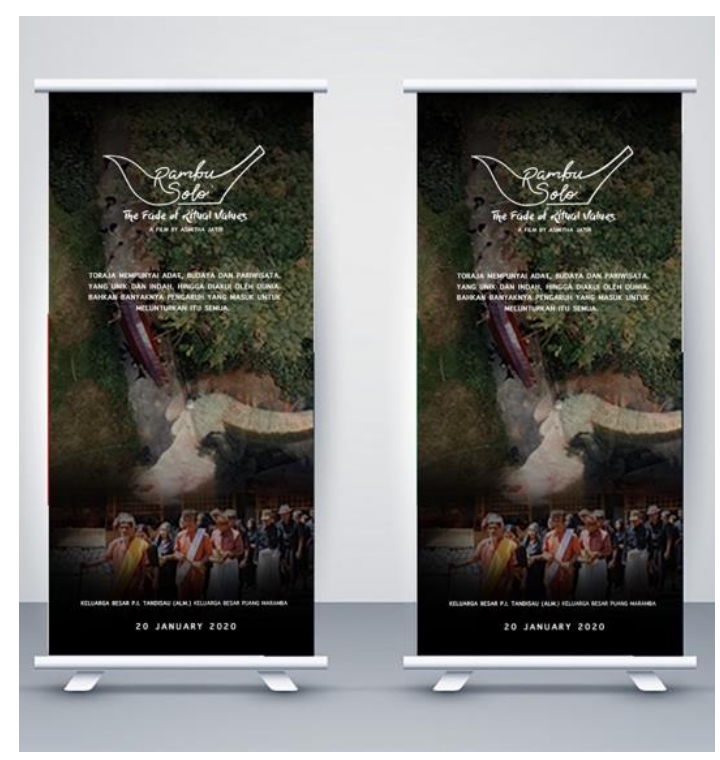

Gambar 37 X-Banner Film

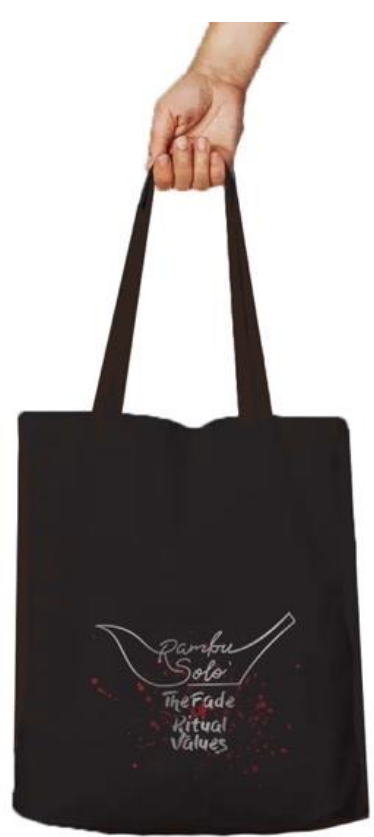

Gambar 38 Totebag Film

\section{KESIMPULAN}

Sesuai dengan paparan hasil film dokumenter upacara Rambu Solo', The Fade of Ritual Valeus maka, pembahasan difokuskan pada lengsernya aluk To' Dolo (kepercayaan nenek moyang) akibat masuknya beberapa budaya lain yang melunturkan nilai-nilai yang ada pada upacara tersebut.

Berdasarkan hasil produksi dapat diketahui bahwa film yang dirancang sesuai dengan yang diharapkan. Maka, dalam pembuatannya ada beberapa tahap yang digunakan seperti pada pembuatan film pada umumnya yang dikemas berbeda tapi tetap sama. Tahap 1 dilakukan pengumpulan data dan analisa yang terkait dengan film seperti, mencari literatur dari buku, observasi lapangan dan wawancara langsung dengan pemuka adat. Tahap 2 eksplorasi ide yang meliputi, naskah, storyline, treatment, storyboard, media pendukung dan media promosi, yang dimana semua sumber inspirasi yang dikemas dalam bentuk naskah maupun sketsa pada film. Tahap 3 implementasi digital yaitu tahapan proses digitalisasi dengan perangkat (keras dan lunak) yang digunakan untuk proses syuting, recording, final design atau editing hingga sampai ke proses rendering 
nantinya. Adapun tahapan dimana film akan dipublikasikan melalui poster serta media social.

Dari hasil penelitian dan perancangan film dokumenter upacara Rambu Solo', nantinya dapat mengubah pola pikir masyarakat Toraja akan pentingnya menjaga sebuah adat dan budaya kita agar tidak dihancurkan dan dicampuri dengan budaya lain (Kristen) karna semua itu adalah titipan dari nenek moyang yang harus dijaga dan dilestarikan. Pesan dan informasi yang terkandung pada film dokumenter upacara Rambu Solo' disampaikan dengan komunikatif dan kreatif dengan berbagai penunjang yang didapatkan dari penelitian mulai dari referensi buku, wawancara dan melihat langsung dari berbagai macam upacara Rambu Solo' yang ada di Toraja. Ditambah dengan teknik sinematografi yang digunakan, juga sound musik dan narasi yang dijamin akan enak dan jelas didengar.

\section{REFERENSI}

(Deff, 2017)

(Hasbi, Sukimi and Mutalib, 2016)

(Pendidikan et al., 2016) 